\title{
INTERDIÇÃO NO BRASIL E NO MUNDO: UMA EXPOSIÇÃO DO DIREITO
}

\section{INTERNACIONAL}

Cláudio Antônio Klaus Júnior ${ }^{1}$

Thiara $Z^{2} n^{2}$

Recebido em 06/096/2019

Aprovado em 07/07/2020

\begin{abstract}
RESUMO
O presente trabalho visa explanar o processo de interdição no Brasil e em outros países mostrando fatores históricos e sociais que influenciaram o aparecimento desta providência drástica, excepcional, no ordenamento jurídico. Juntamente com um panorama da jurisprudência no tema, breve explicação sobre a capacidade civil e a ideia de ação inspirada por este trabalho.

Palavras Chave: Interdição, Direito Civil.
\end{abstract}

\section{INTERDICTION IN BRAZIL AND IN THE WORLD: AN EXPOSURE OF}

\author{
INTERNATIONAL LAW
}

\section{ABSTRACT}

This paper aims to explain the judicial interdiction process in Brazil and in other countries around the world, showing historical and social factors that influenced the emergence of this drastic, exceptional provision in the civil law system. Along with a panorama of national jurisprudence on the subject, brief explanation on the civil capacity and idea of action inspired by this work.

Keywords: Interdiction, Civil Law.

\section{INTRODUÇÃO}

O termo interdição - derivado do latim interdictio, do verbo interdicere, proibir, interdizer, vedar - significa, em termos amplos, toda proibição de fazer alguma coisa ou praticar um

\footnotetext{
${ }^{1}$ Acadêmico do curso de Relações Internacionais do Centro Universitário Internacional UNINTER, Pesquisador do Programa de Iniciação Científica do Centro Universitário Internacional UNINTER, Acadêmico do curso de Direito da Universidade Alto Vale do Rio do Peixe - UNIARP

${ }^{2}$ Mestranda em Desenvolvimento e Sociedade linha de pesquisa Sociedade, Cidadania e Segurança Pública Uniarp (2019). Especialista em Direito do Trabalho e Previdenciário, UNIARP - Universidade Alto Vale do Rio do Peixe (2011). Possui graduação em Direito pela Universidade do Contestado(2005). Atuou como advogada e orientadora do Estágio Supervisionado do Núcleo de Práticas Jurídicas do Curso de Direito da UNIARP Universidade Alto Vale do Rio do Peixe (2010-2019). É advogada atuante na área Cível. Conselheira Suplente da Subseção de Caçador da Ordem dos Advogados do Brasil. Docente de Ensino Superior nas disciplinas de Direito Civil - Parte Geral, Direito das Obrigações, Contratos e Direito Processual Civil na UNIARP Universidade Alto Vale do Rio do Peixe, Campus Caçador e Fraiburgo.
} 
ato. Além da acepção genérica, o vocábulo interdição detém significados jurídicos; entre estes, o que agora tem relevância é aquele de ato judicial pelo qual a autoridade competente, designado um curador, declara a incapacidade civil da pessoa maior, que fica impedida da prática de atos jurídicos relativos à sua própria pessoa e à livre disposição de bens. Neste trabalho serão expostos aspectos gerais da interdição, o processo necessário para obtenção de tal e também outras curiosidades sobre o assunto no Brasil e no mundo além de suas consequências.

\section{BREVE HISTÓRICO DA INTERDIÇÃO, CURATELA E TUTELA}

Da patrimonialidade verificada na história - Em linhas gerais, a curatela consiste em um encargo suportado por alguém, que deverá administrar a pessoa e os bens de um sujeito que incapaz de fazê-lo por si mesmo. Ao curador competirá o exercício dos atos civis tendentes à concretização e o gozo dos direitos por parte do curatelado. A origem e a existência do instituto da curatela remontam a tempos antigos. Na Lei das XII Tábuas, precisamente no item oito da "Tábua V - Das Herança e Tutelas", tinha-se que: "8. Se alguém torna-se louco ou pródigo e nato tem tutor, que a sua pessoa e seus bens, sejam confiados à curatela dos aguados e, se não há agnados, à dos gentis." Ao longo dos anos, a curatela se desenvolveu e se consolidou tal como se nos afigura, de modo semelhante em todos os países que seguiram a tradição romano-germânica.

No Brasil, sua aplicação é prevista desde os tempos coloniais, com as Ordenações Filipinas, cujo teor é praticamente repetido pelo Código Civil de 1916. As Ordenações Filipinas tratavam da matéria cível no Livro Quarto, cujo título CIII dispunha sobre a curatela, definindo as circunstâncias que a ensejavam e as regras sobre a nomeação do curador. Assim estabelecia a legislação portuguesa: "Porque além dos Curadores, que hão de ser dados aos menores de vinte e cinco anos, se devem também dar Curadores aos Desasisados e desmemoriados, e aos Prodigos, que mal gastarem suas fazendas."

Digitalização do Quarto Livro das Ordenações Filipinas - CIII 

Tutor novo tudo o que per conta for achado, que deve. ao orfáo.

E assi se faca cada vez que algum Tutor for removido, ou dado outro de novo(1).

$$
\text { M.-liv. } 1 \text { t. } 67 \text { \& } 29 .
$$

10. E se algum Tutor, não sendo pa-

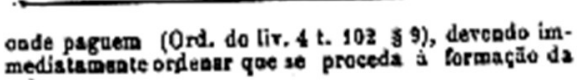
culps.; O.. D. 249 - de 31 de Agooto do 1355 tratando so. bre disposiçoes relativas a arrec

- E por esta occassiajo obserys a Sr. Iarpector (da Tiewuraria do Sorgipe) qoe embora sejo da compe:leacia dos Juires de Orphecos recorrer a prizio dos Cupadores, al forma da Ord. do liv. coradores o mais Agentes bscase corre a obrigaçâdo de roquert-la a quelles nos casos em que so davk verillear; ttse attribuiçio lodaria alo prejudica g diceilo qae cabe soe Inspectorea das Thezourtiak de applicario

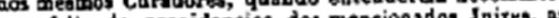
o da talta de providencia dar meacionsdos daises, Fonte: http://www1.ci.uc.pt/ihti/proj/filipinas/14p994.htm

rente do orfac(1), quizer ter a Tutoria mais - Juiz que a administrou bem 0 tempo passado, e que he abonado para isso, e que nào ha outra causa para lhe dever ser tirada(2), deixar-lhe-ha ter a dita Tuloria, em quanto 0 .bem fizer, e bem parecer ao Juiz(3).

$$
\text { y. - It. I t. } 87530 .
$$

\section{TITULO CIII.}

\section{Dos Curadores, que se dio aos Prodigos e Mentecaptos(b).}

Porque alem dos Curadores, que hà de ser dados aos menores le vinte cinco annos $(3)$, se devem lambem dar Curadores $(6)$ aos Desasisados e desmemoriados $(\mathbf{T})$, e aos Prodigos(8), que mal gastarem suas fazendas.

Mandamos que tantu que o Juiz dos Orfăos souber que em sua jurisdicçio ha algum Sandeu, que por causa de sua sandice possa da cadea com effeito pague, $\theta$ entregue a tempo, que os ditos dous annos, achando

Com base nesta citação, pode-se observar que algumas características do instituto da curatela no ordenamento jurídico nacional atual têm raízes nas Ordenações Filipinas. Uma das características históricas que podem ser observadas é a que respeito ao caráter patrimonial atribuído à curatela, cuja principal preocupação é a tutela e administração dos bens do curatelado.

\section{CAPACIDADE CIVIL}

O código civil brasileiro regula as capacidades por meio de seus primeiros artigos:

"Art. $2^{\circ}, \mathrm{CC}$ : A personalidade civil da pessoa começa do nascimento com vida; mas a lei põe a salvo, desde a concepção, os direitos do nascituro.”

De acordo com a doutrina, o conceito de capacidade comporta a seguinte subdivisão: a) CAPACIDADE DE DIREITO (GOZO) -> é a própria aptidão para o exercício de direitos civis. Quem tem capacidade, possui capacidade de direito. b) CAPACIDADE DE FATO (EXERCÍCIO) -> é a capacidade de praticar atos pessoalmente. Todas as pessoas, de modo geral, tornam-se capazes ao completar 18 anos de idade, o Código Civil traz as exceções à regra:

Art. 4ํ São incapazes, relativamente a certos atos ou à maneira de os exercer:

I - os maiores de dezesseis e menores de dezoito anos;

II - os ébrios habituais e os viciados em tóxico;

III - aqueles que, por causa transitória ou permanente, não puderem exprimir sua vontade;

IV - os pródigos. 
Parágrafo único. A capacidade dos indígenas será regulada por legislação especial.”

As pessoas que se enquadram nos incisos de II a IV tornam-se relativamente capazes somente após o processo de interdição que será explicado neste trabalho.

\section{A INTERDIÇÃ̃o}

A interdição é um instituto que teve origem no direito romano. É uma ação intentada no âmbito cível e tem por fim a declaração da incapacidade de determinada pessoa. Uma vez decretada a interdição pelo magistrado, o interditado não mais poderá comandar os atos na vida civil, portanto, fazse necessário a nomeação de um curador, o que é feito na mesma ação de interdição. A incapacidade no Brasil ocorre por dois critérios: objetivo, pela idade, e subjetivo, pelo psicológico. As pessoas menores de 18 anos são consideradas incapazes e não é necessária nenhuma medida para o reconhecimento dessa incapacidade. Já para considerar um maior de idade incapaz, por ser uma exceção, é necessário seguir as regras da "ação de interdição".

Segundo ZARIAS (Alexandre Zarias, 2003), A interdição não possui eficácia retroativa, isto é, não se fixa a incapacidade do interdito em data anterior à sentença, mas a partir dela. A interdição, enfim, modifica o status da personalidade jurídica de uma pessoa de "capaz" para incapaz".

A interdição pode ser absoluta ou parcial. A absoluta impede que o interditado exerça todo e qualquer ato da vida civil sem que esteja representado por seu curador. Já a interdição parcial permite que o interditado exerça aqueles atos a que não foi considerado incapaz de exercê-lo nos limites fixados em sentença.

Os relativamente incapazes podem praticar atos e negócios jurídicos, desde que devidamente assistidos por seu responsável legal. À semelhança do que ocorre com os absolutamente incapazes, serão responsáveis legais do relativamente incapaz seus pais. $\mathrm{Na}$ falta deles, o tutor ou o curador, conforme for o caso. Não havendo pessoa que detém o poder familiar para representar ou assistir o incapaz, dar-se-á tutela para os incapazes por idade; e curatela, para os demais, mediante decisão judicial proferida no processo de interdição.

Nos processos de interdição judicial, abolem-se os direitos do indivíduo em nome do seu direito de ser tutelado (leia-se protegido). Interditado, o indivíduo não pode mais administrar seus bens, nem a sua pessoa e não pode votar também. E como fica este sujeito nomeado louco (ou doente) pela família em função de uma determinada história? Geralmente perde suas próprias referências e tornase totalmente dependente e submisso ao curador. Paradoxalmente, o judiciário aceita pedidos de desinterdição feitos pelos próprios interditados. Talvez mea culpa. Entretanto, são muito raros estes 
pedidos e mais rara ainda a desinterdição.

Apesar das ressalvas anteriormente elencadas, não podemos adotar a postura ingênua de considerar a interdição como um mal que deve ser combatido a todo custo. Em outras palavras, o instituto da interdição, embora deva ser visto com reserva e moderação, necessita ser desmistificado e, quando utilizado, respeitando sempre o princípio da dignidade da pessoa humana. Na hipótese de alienação, arrendamento ou qualquer outra forma de comercialização do patrimônio do interdito, será exigida prévia avaliação judicial do bem, podendo, em alguns casos, ser admitida estimativa particular elaborada a pedido do próprio curador. O numerário arrecadado, entretanto, será objeto de depósito judicial, vinculado ao processo - em nome do interdito, cabendo a todo tempo sua efetiva movimentação, desde que justificada a necessidade. Vale dizer que tais ações não devem ser usadas indiscriminadamente. Isso porque, ao final, o juiz dará uma sentença que atingirá a liberdade e a intimidade da pessoa interditada (que será declarada incapaz). É preciso que o interesse não seja exclusivamente financeiro, mas sim proteger a dignidade do próprio interditando, não o interesse de terceiros.

Curiosidade: A pessoa interditada pode ser recolhida em estabelecimento?

O artigo 1.777 do CC prevê que as pessoas sob curatela devem ter preservado o direito à convivência familiar e comunitária e, portanto, deve-se evitar o seu recolhimento em estabelecimento que os afaste desse convívio.

A interdição, cessando a causa que a determinou, pode ser levantada. $\mathrm{O}$ pedido de levantamento pode ser feito pelo interditado, sendo apensado aos autos da interdição. O juiz nomeia perito para proceder ao exame de sanidade no interditado e após a apresentação do laudo designa audiência de instrução e julgamento. Acolhido o pedido, o juiz decreta o levantamento da interdição e manda publicar a sentença, após o trânsito em julgado, pela imprensa local e órgão oficial por três vezes, com intervalo de 10 (dez) dias, seguindo-se a averbação no Registro Civil das Pessoas Naturais (Código de Processo Civil, artigo 1.186).

\section{ORDENAMENTOS JURÍDICOS INTERNACIONAIS}

Os ordenamentos jurídicos de países europeus como Portugal, Itália e França não fazem qualquer referência à toxicomania ou à embriaguez habitual como elementos a serem sopesados para a qualificação da capacidade jurídica do indivíduo. Em verdade, Portugal $^{1}$ e Itália $^{2}$ referenciam o uso de bebidas alcoólicas ou de estupefacientes como causas para a inabilitação do sujeito, instituto que teria repercussões inferiores aos da interdição, impossibilitando o indivíduo de exercer somente os atos 
de disposição de bens e outros fixados em sentença (Cf. PINTO, 2005, p. 242). Contudo, nas hipóteses analisadas, não se visualizaria causa para o estabelecimento da imputação de ser inserido no rol dos relativamente incapazes. As referidas ordens jurídicas apresentam a questão de maneira diversa, não vinculando incapacidades aos regimes de interdição do indivíduo. A questão no Direito francês não se dá de maneira muito diversa. Apesar de não existir uma previsão específica acerca da embriaguez habitual e da toxicomania, poder-se-ia aplicar a esses casos o artigo 425, do Code Civil, que prevê a possibilidade de utilização da proteção da curatela para aqueles que, em razão de uma alteração em suas faculdades mentais ou corporais, ficarem impedidos de exercer a sua vontade. Logo, se os toxicômanos ou ébrios habituais não tiverem o necessário discernimento para manifestar o seu arbítrio, nada impede que sejam submetidos à curatela.

Constata-se, portanto, que a ordem jurídica brasileira acabou por incorporar uma sistemática diferenciada de outros países de origem romano-germânica. $\mathrm{O}$ tratamento oferecido aos alcoólatras e toxicômanos é realizado na Parte Geral do Código Civil, dentro de preceitos relativos à capacidade civil. Posteriormente, o tema é retomado na Parte Especial, na definição dos indivíduos que podem ser submetidos à curatela. Essa sistematização, no entanto, parece não guardar coerência lógica ou mesmo utilidade do ponto de vista prático. Nesse ponto, parece ser prescindível a qualificação a priori em diferentes graus de capacidade jurídica, notadamente, no que concerne aos alcoólatras e toxicômanos. Não se percebe qualquer serventia na denominação de um sujeito como relativamente incapaz, quando a própria codificação abre espaço para o impedimento de exercício de atos de disposição, objetivando a sua proteção por meio da curatela.

${ }^{1}$ Art. 152. Podem ser inabilitados os indivíduos cuja anomalia psíquica, surdez-mudez ou cegueira, embora de carácter permanente, não seja de tal modo grave que justifique a sua interdição, assim como aqueles que, pela sua habitual prodigalidade ou pelo uso de bebidas alcoólicas ou de estupefacientes, se mostrem incapazes de reger convenientemente o seu patrimônio.

${ }^{2}$ Art. 415 Persone che possono essere inabilitate Il maggiore di età infermo di mente, lo stato del quale non è talmente grave da far luogo all'interdizione, può essere inabilitato (417 e seguenti, 429). Possono anche essere inabilitati coloro che, per prodigalità (776) o per abuso abituale di bevande alcoliche o di stupefacenti, espongono sé e la loro famiglia a gravi pregiudizi economici. Possono infine essere inabilitati il sordomuto e il cieco dalla nascita o dalla prima infanzia, se non hanno ricevuto un'educazione sufficiente, salva l'applicazione dell'art. 414 quando risulta che essi sono del tutto incapaci di provvedere ai propri interessi. Article 425 Toute personne dans l'impossibilité de pourvoir seule à ses intérêts en raison d'une altération, médicalement constatée, soit de ses facultés mentales, soit de ses facultés corporelles de nature à empêcher l'expression de sa volonté peut bénéficier d'une mesure de protection juridique prévue au présent chapitre. S'il n'en est disposé autrement, la mesure est destinée à la protection tant de la personne que des intérêts patrimoniaux de celle-ci. Elle peut toutefois être limitée expressément à l'une de ces deux missions.

$\mathrm{Na}$ África do Sul, por exemplo, existem três categorias diferentes de curadores: Curador 
ad litem - curador de "contencioso". Este curador litiga em nome do paciente; Curador bonis - um curador de mercadorias. Este curador protege os interesses financeiros e proprietários do paciente; e Curador ad personam - um curador para a pessoa. Este curador cuida das necessidades diárias do paciente, por exemplo, necessidades que surgem em um centro de atendimento onde o paciente pode residir. De acordo com o Artigo 57 das Regras Uniformes do Tribunal, pede-se então ao Supremo Tribunal que faça uma ordem declarando que o paciente é desatento e incapaz de gerir os seus próprios assuntos. Declarações de apoio de dois médicos, dos quais um deve ser psiquiatra, devem ser fornecidos. É imperativo lembrar que na África do Sul, não há procuração legal duradoura. Assim, se o paciente tiver dado a um membro da família ou a um amigo uma procuração para agir em seu nome, essa procuração desaparece se a capacidade mental do paciente diminuir abaixo do limite legal. Se essa pessoa continuar a agir em termos da procuração, suas ações resultarão em fraude.

Há países como a Alemanha, por exemplo, que reservam quase 150 artigos de seu código civil para regular o assunto, conforme demonstra Patrícia Ruy Vieira em um interessante artigo publicado na Revista dos Tribunais $n^{\circ}$ 826. O Código Civil (LGL 2002\400) alemão, conhecido como "BGB" (Bürgerliches Gesetzbuch Beurkundungs), estabelece as normas relativas à tutela e curatela dos arts. 1.773 a 1.921. São, portanto, quase cento e cinqüenta artigos destinados à proteção do menor ou maior incapaz; o Código Civil (LGL 2002\400) brasileiro, tanto aquele vigente até 2002 como o atualmente em vigor, reserva pouco mais de cinquenta artigos para os mesmos institutos jurídicos.

No tocante à curatela, a legislação alemã prevê a necessidade de autorização judicial específica para diferentes atos relacionados à vida civil, e atos destinados ao tratamento médico do portador da enfermidade mental. Tal previsão visa a proteger o incapaz, possibilitando-lhe, sempre que possível, que tome suas próprias decisões. Com essa medida, graduam-se os atos e decisões, não se estendendo a curatela, indiscriminadamente, a qualquer ato da vida do indivíduo considerado incapaz. O direito brasileiro, no entanto, não prevê a distinção de atos que prescindam de decisão judicial prévia. Declarada a incapacidade do indivíduo, será decretada sua interdição: se a interdição for absoluta, todos os atos jurídicos deverão ser, indistintamente, praticados pelo curador; se parcial a interdição, deverão ser estabelecidos os limites da curatela, especificando-se a esfera de atuação do curador. Neste país, o legislador procurou, ao máximo, privilegiar a tomada de decisões pelo próprio incapaz, nos casos em que isso for possível. Assim, há atos que podem ser praticados por ele mediante autorização judicial.

Nos Estados Unidos, alguns Estados fundamentam suas normas de proteção ao incapaz no Uniform Probate Code - UPC, proposto e aprovado em 1969 pela National Conference of Commissioners on Uniform Law (NCCUSL), e destinado a uniformizar as normas de propriedade da família, abordando temas como a proteção de menores, idosos e portadores de doenças ou deficiências mentais. O UPC objetiva, pois, atualizar e simplificar os aspectos legais nos Estados, surgindo como 
uma recomendação de uniformização legislativa. O UPC foi revisado substancialmente em 1975, 1982, 1987, 1989, 1990 e 1991, sendo que atualmente é adotado nos seguintes Estados: Alaska, Arizona, Colorado, Havaí, Idaho, Maine, Michigan, Minnesota, Montana, Nebraska, New Jersey, New Mexico, Dakota do Norte, Dakota do Sul, Pensilvânia, Carolina do Sul, Utah e Winsconsin.

Houve, a partir de então, uma diferenciação entre o instituto denominado Guardianship, destinado a proteger o ser humano, inclusive no tocante à realização de tratamento médico, e o conservatorship, curatela do Estado na proteção dos bens do portador da enfermidade mental. Roger Peters, Schmidt e Miller 28 indicam que, na maioria dos Estados americanos, o processo de interdição se desenvolve em duas etapas: um estágio inicial, que consiste na realização de depoimentos necessários para o exame e discussão dos critérios de incapacidade de determinado indivíduo para os negócios, a gestão do patrimônio ou condução de assuntos particulares. A Corte verificará a extensão da incapacidade física ou mental apresentada pelo indivíduo e a eventual disponibilidade de recursos humanos na supervisão das incapacidades. O estágio subseqüente consiste na oitiva do curador, seja ele privado ou público, para a determinação de suas responsabilidades.

\section{REFERÊNCIAS BIBLIOGRÁFICAS}

ABRAHAM \& GROSS: ATTONEYS - NOTARIES - CONVEYANCERS. Curatorship what does it entail. Disponível em: <http://www.abgross.co.za/curatorship-what-does-itentail/>. Acesso em: 03 ago. 2018.

ANOREG - ASSOCIAÇÃO DOS NOTÁRIOS E REGISTRADORES DO BRASIL.

Interdição. Disponível em: <https://www.anoreg.org.br/site/atos-extrajudiciais/registrocivil/interdicao/>. Acesso em: 02 ago. 2018.

Donizetti, Elpídio Curso didático de direito civil / Elpídio Donizetti; Felipe Quintella. - 7. ed. rev. e atual. - São Paulo: Atlas, 2018.

Gagliano, Pablo Stolze Manual de direito civil; volume único / Pablo Stolze Gagliano e Rodolfo Pamplona Filho. - São Paulo : Saraiva, 2017. 1. Direito civil 2. Direito civil - Brasil I. Título II. Pamplona Filho, Rodolfo. 16-1508 CDU 347(81)

Lisboa, Roberto Senise Direito civil de A a Z / Roberto Senise Lisboa. -- Barueri, SP:Manole, 2008.

Salomão, Luis Felipe Direito civil: diálogos entre a doutrina e a jurisprudência / Anderson Schreiber... [et. al.]; coord. Luis Felipe Salomão, Flávio Tartuce. - 1. ed. - São Paulo : Atlas, 2018.

TV JUSTIÇA :: STF - SUPREMO TRIBUNAL FEDERAL. Revista do advogado.

Disponível em:

$<$ http://www.stf.jus.br/repositorio/cms/portaltvjustica/portaltvjusticanoticia/anexo/revista_do_ advogado.pdf $>$. Acesso em: 02 ago. 2018. 
SOUZA Iara Antunes SOUZA; SILVA Michelle Danielle Cândida. Capacidade civil, interdição e curatela: As implicações jurídicas da Lei n. 13.146/2015 para a pessoa com deficiência mental. REVISTA DA FACULDADE DE DIREITO DA UFRGS, Porto Alegre-RS, n. 37, out./dez. 2017. Disponível em: <https://cebid.com.br/wpcontent/uploads/2018/03/77546-329374-1-PB.pdf>. Acesso em: 03 ago. 2018.

VIEIRA, Patrícia Ruy. A interdição civil no direito brasileiro. Revista dos tribunais, Cidade, v. 826/2004, p. 93 - 116, jan. 2012. Disponível em:

$<$ https://drive.google.com/file/d/1gov5tnxlosnqd1wilzfbsuanmx3hifza/view $>$.Acesso em: 12 jan. 2012.

TNH1. Como funciona a interdição de uma pessoa no brasil. Disponível em:

$<$ http://www.tnh1.com.br/noticias/noticias-detalhe/brasil/como-funciona-a-interdicao-deuma-pessoa-no-brasil/?chash $=\mathrm{c} 2147 \mathrm{dbde} 1 \mathrm{e} 8 \mathrm{~b} 85 \mathrm{a} 746537 \mathrm{a} 04527 \mathrm{a} 8 \mathrm{~b} 5>$. Acesso em: 03 ago. 2018.

MOVIMENTO DOWN. Interdição da pessoa com deficiência intelectual - tutela e curatela. Disponível em: <http://www.movimentodown.org.br/2013/02/interdicao-da-pessoacom-deficiencia-intelectual-tutela-e-curatela/>. Acesso em: 03 ago. 2018.

MINISTÉRIO PÚBLICO DO ESTADO DO ESPÍRITO SANTO. Interdição parcial é mais legal . Disponível em: $<$ https://www.mpes.mp.br/arquivos/anexos/03429770-cdf2-4bf7-9cd874bc7c5cca04.pdf>. Acesso em: 03 ago. 2018.

UNIVERSIDADE FEDERAL FLUMINENSE - UFF. Tese de doutorado de professora da uff vira lei no novo código de processo civil brasileiro (2015). Disponível em:

$<$ http://www.uff.br/?q=noticias/05-10-2015/tese-de-doutorado-de-professora-da-uff-vira-leino-novo-codigo-de-processo-civil>. Acesso em: 03 ago. 2018.

ZARIAS, Alexandre. Negocio publico e interesse privado: analise dos processos de interdição. 2003. 227 p. Dissertação (mestrado) - Universidade Estadual de Campinas, Instituto de Filosofia e Ciencias Humanas, Campinas, SP. Disponível em:

$<$ http://www.repositorio.unicamp.br/handle/REPOSIP/281379>. Acesso em: 3 ago. 2018.

UFF BR. A flexibilização da curatela para o psicopata: uma interpretação constitucional pelo superior tribunal de justiça. Disponível em: <http://ppgdc.sites.uff.br/wpcontent/uploads/sites/34/2017/06/197-245-1-sm.pdf>. Acesso em: 06 ago. 2018. 